\title{
Marketing campaign systems - the secret to life-long customer loyalty
}

Received: 14th December, 2001

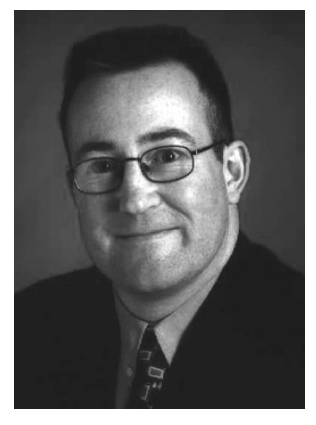

\section{Roger Luxton}

is Head of Consultancy at marketing services and campaign management company, MarkIT Information Services Limited. He was previously Analytics Director at worldwide direct marketing company Brann Data, and has held a number of marketing roles in both consumer and business-to-business companies. He is also a member of the Institute of Direct Marketing.

Abstract Despite the growing availability of customer data, many companies do not carry out data analysis, and according to PricewaterhouseCoopers (PWC), 54 per cent of 159 companies surveyed admitted they have no system for managing campaigns. ${ }^{1}$ For most, analysis is not top of the agenda. Companies are typically focusing so intently on the gathering of data they are neglecting to consider why they are collecting them and therefore also failing to put them to effective use in subsequent marketing campaigns. The 'nice to have' rather than the 'need to know' approach to customer data is to blame.

This paper outlines the case for the development of a dynamic marketing strategy and details the key steps, technologies and strategies required to achieve this. It seeks to illustrate the importance of marketing campaign systems and analysis in the battle to understand customer data and ensure life-long customer loyalty. Also presented is a customer case study illustrating the real-life effectiveness of technology and strategy in harnessing the value of customer data.

\section{INTRODUCTION}

Today's consumer is not so much hard to locate as difficult to please. Any organisation that sells products or services needs to know who its customers are. More importantly, however, it needs to know about its customers and prospects so that it can meet and exceed their expectations and service them appropriately. Many companies have taken positive steps to ensure that this happens. In fact, according to IDC, expenditure on customer relationship management (CRM) applications alone soared 84 per cent in 2000 , to $\$ 6.2 \mathrm{bn} .^{2}$

A steady increase in awareness about the importance of CRM has led many companies to invest in solutions to ensure that they diligently pool these business-critical customer data. IDC forecasts worldwide revenues generated from CRM data warehousing software and services will explode from under $\$ 4.2$ bn in 1999 to over $\$ 20$ bn by $2004 .^{3}$

As a result, marketers have never had so much data available to help them understand the characteristics, behaviour and attitudes of their customers. Many months and millions of pounds later, however, organisations are finding themselves in a quandary. Data silos have built up, filing cabinets are fit to burst with customer information, yet they are despairing. They are no closer to 
understanding their customers. Why? Because very little, if any, of these data ever get turned into usable, and therefore valuable information.

Simply amassing data is not enough any more. They must be analysed.

Without analysis it remains impossible for marketers fully to understand customers and then target them appropriately, increase their lifetime value or respond effectively to their requirements. Therefore, despite long-term, high-cost CRM initiatives, most companies still struggle to explain their customers' current and past behaviour and, importantly, predict their future behaviour. A lack of a dynamic marketing strategy, using customer analysis to drive appropriate marketing campaigns, is responsible. In the PWC study mentioned earlier, of the 159 companies surveyed only 5 per cent of firms use full-service campaign management software. ${ }^{4}$

As today's increasingly competitive marketplace makes the struggle to gain competitive advantage and guarantee customer loyalty harder than ever, it has never been more crucial to be able to analyse customer information and put it to effective use in marketing campaigns.

This problem is exacerbated by today's multimedia marketplace. Reaching the target customer through just a couple of media channels is no longer feasible. The explosion of media outlets, the Internet, interactive advertising and other innovations are all competing with traditional channels for the attention of impatient consumers.

In response to such choice, customers' demands are increasing as never before. Expecting better targeted and personalised marketing communications with the right frequency, customers want to be able to use any channel or touch point, whenever they want, wherever they are and are all too eager to shift loyalty if dissatisfied. Marketers must therefore find ways of working smarter if they are to coordinate disparate customer information, ensure customer loyalty and have a high marketing campaign success rate in an increasingly fragmented and sophisticated market.

\section{HOW TO IMPROVE MARKETING AND COPE WITH CHANGE}

The challenge of campaign management is simple - if the business does not give customers what they want the business is doomed to deliver under-performing campaigns and lose the fight for customer loyalty. In the battle for marketing supremacy, only those companies that exploit data, technology and processes will be triumphant.

Marketers must challenge existing ways of working if they are to improve marketing performance, understand customers and maximise productivity. At present, too many companies do not use data actively, do not have the technology in place to carry out analysis or campaign management and do not have effective processes. For many organisations, the answer begins with automating the basics - the re-running of campaigns and post-campaign analysis for example - so that more time can be spent thinking and planning rather than manipulating data or producing statistics. With the right data, the right technology and the right processes, marketers can truly understand their customers, personalise their marketing efforts and drive higher returns on marketing investment.

Overcoming the inertia hurdle and deciding to automate processes by choosing and purchasing marketing campaign technology is the first step. To help them work smarter, increase productivity, and to cater for heightened customer expectations, companies must 


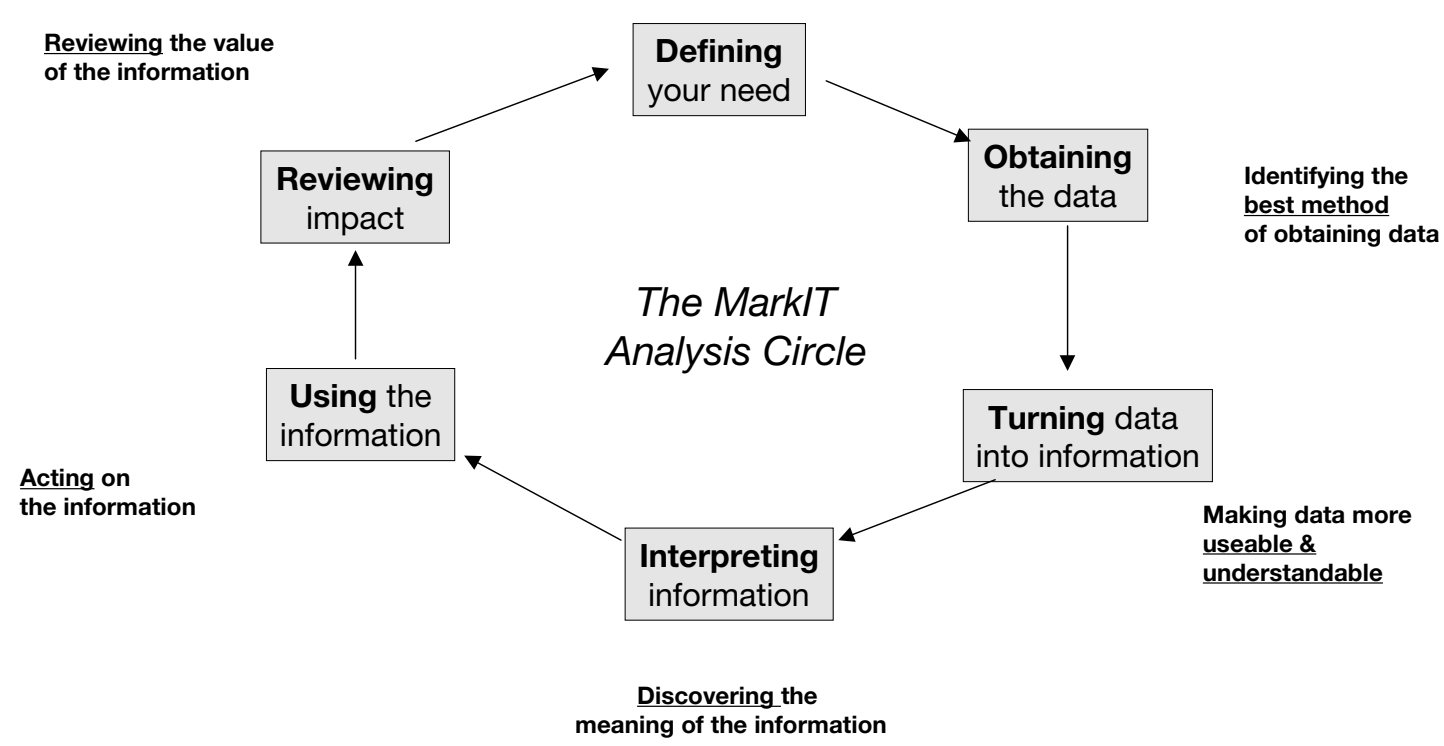

Figure 1: Identifying why information is needed and specifying the question that needs answering

deploy campaign management tools with integrated analysis — marketing campaign systems - to help them plan and execute their marketing campaigns and manage the entire campaign process from start to finish. These tools also help identify the most appropriate media and targets for individual campaigns, evaluate probable success rates, execute the campaign logistics and undertake vital post-campaign analysis. Without technology, most companies will not be able to deliver the personalised and targeted contact strategies required to maximise the potential of their customers.

Companies that have a large target customer base are especially in need of a marketing campaign system that can help them manage multiple campaigns, especially if they run in parallel and in quick succession. Disparate systems are often not the most efficient way of planning and executing complex campaigns as information has to be extracted from many different sources, which will not necessarily be compatible, and the ability to manipulate and relate these data streams will be reduced. Marketing campaign systems, with integrated analysis functions, help to improve the quality of campaign execution and speed of post-campaign analysis, by providing a seamless integration of all the campaign elements (see Figure 1). Conducting analysis in a separate system not only adds an extra process, but also leads to discrepancies in the results. Unifying analysis enables accurate data alignment, easier analysis and a faster and more in-depth way of analysing respondents. It also enables organisations to integrate the respondent data with future campaigns to improve information on customers continually and hence move them closer to their target audience.

Designed to consolidate the information held in disparate spreadsheets, planning documents, databases and other analytical systems and data warehouses, marketing campaign systems utilise the information to plan, manage and track marketing campaigns. By avoiding re-keying of data, movement of data, and selections, 
External data Company Databases

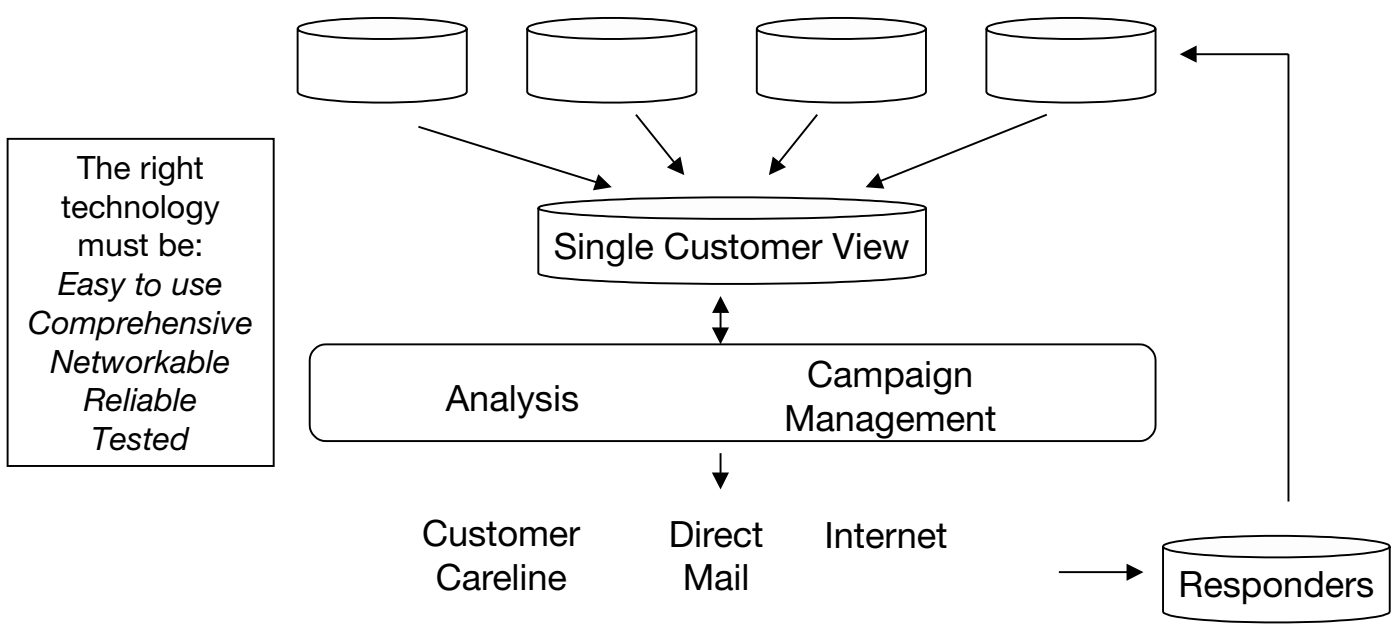

Figure 2: The right technology

marketers can devote more time to planning than to button pushing. This integration of the marketing process (as shown in Figure 2) enables customer communications across multiple touch points, such as direct mail, telemarketing and web to be managed and monitored and the design, execution, assessment and refinement of highly segmented campaigns to be automated. Integration among numerous customer touch points was cited as a problem by 67 per cent of marketers in the USA and UK, according to Accenture. ${ }^{5}$

Marketing campaign systems help improve the quality of campaign execution and speed of post-campaign analysis, by providing a seamless integration between customer data and campaign elements such as campaign planning and evaluation. Fifty-seven per cent of 175 senior marketing executives surveyed by Accenture conceded their campaigns are not integrated or even coordinated with other areas of the company with which customers also interact and 65 per cent struggled to integrate and share customer data across the organisation to develop a single view of the customer. ${ }^{6}$

\section{ANALYSE AND ACT}

Investment in technology alone is, however, useless. It must also be supported by investment in processes - analysis, planning, execution and evaluation - and data. Unfortunately, many companies are focused so intently on gathering customer data they neglect to consider what they are collecting and why. The 'nice to have' rather than the 'need to know' approach to data collection and analysis is to blame. Too often focused on the 'big picture', firms are awash with information on product performance or sales by channel and few have a top-level view of their customer base. Asking which customers are most profitable or who is most likely to leave generally gets a blank stare. Too many companies just do not interrogate their data in that way.

Problems typically arise with analysis because companies are poor at knowing what they want information or analysis for, ie defining the need. 'We have a big database and I want it to tell me interesting things', 'I want to know more about my customers - but I don't know what' are typical responses when 


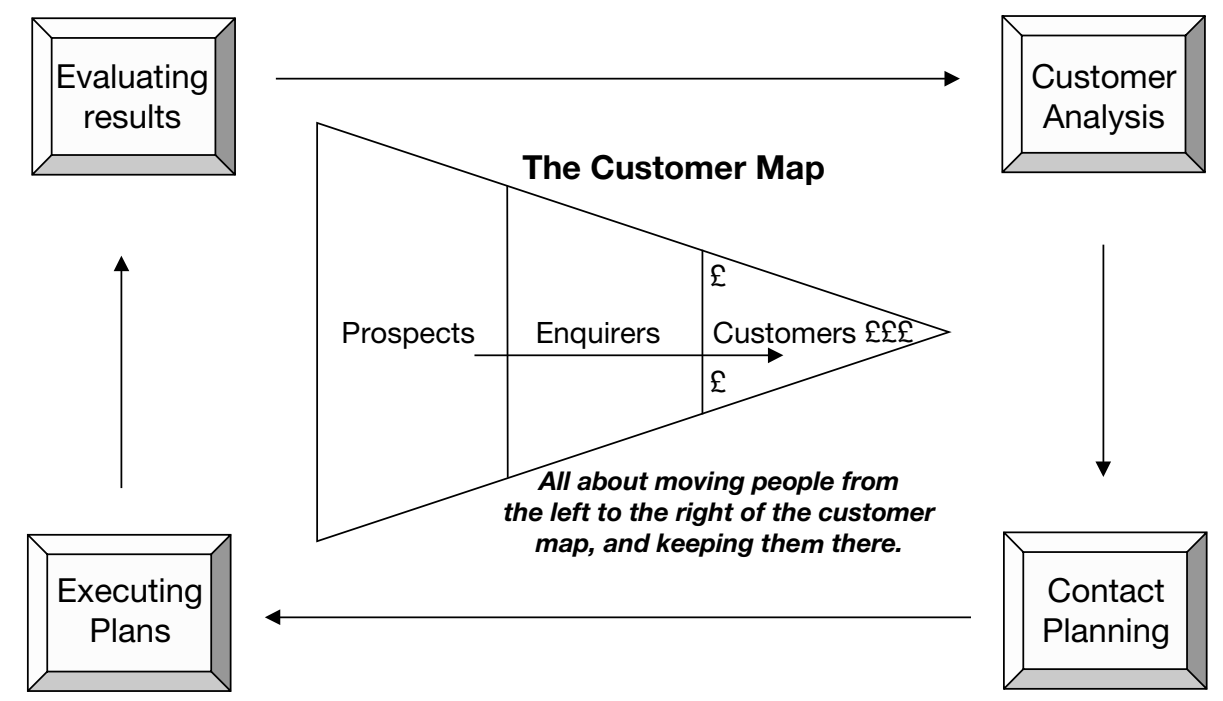

Figure 3: The right processes

marketing departments are pushed to provide a brief to analysts or consultants. With such an insubstantial brief, whoever performs the analysis - an external company, a member of the information technology (IT) department or an internal marketing analyst - can do little more than endlessly churn out meaningless data.

Unfortunately, the end result is then not worth the paper it is written on and is consequently put into the filing cabinet rather than used to improve subsequent marketing activity. Most companies require a range of analysis. For example, pre-campaign analysis is essential if a business wishes to understand its audience, make detailed selections and counts and carry out post-campaign analysis. Strategic analysis on the other hand helps the business understand issues from the top down, as for example, if it has an acquisition or lapsing problem or is failing to win certain types of customers.

The tactical approach to analysis that companies typically adopt also perpetuates this problem. More often than not, analysis is not planned and companies do not think proactively about the long-term benefits. Rather, it is conducted in a rush and is highly reactive - usually just before a new product is to be launched - as a means to a short-term end. It is important to establish a few important details first: What does the firm want to know? Who does it need to understand? What is most important and what is just nice to know? How much is it worth spending? When is it needed? How accurate does it need to be? Producing great analysis usually requires several iterations, so it is essential to allow time to think, plan and execute the work.

Figure 3 illustrates a structure process to use when tackling analysis. By applying this six-stage process companies can better exploit data and lessen some of the problems.

The biggest problem for marketers in campaigns is data and successful analysis certainly depends on them. Sixty-eight per cent of UK executives in the Accenture study said they often have problems transforming overwhelming amounts of data into actionable customer insight. ${ }^{7}$ With the wrong data resources 
are wasted, sales are poor and customers are lost. Data must be easy to load, comprehensive, able to be enhanced, refreshable and traceable. Basic customer data can be enhanced with geographic, lifestyle and modelling data to identify the most likely candidates for buying products or services, but with the right marketing campaign system, this information can also be easily combined to build profiles to help 'best-fit' sales opportunities. Armed with this information, organisations can be proactive in their marketing efforts, leading to increased revenue and better levels of customer satisfaction.

Once data are amassed companies are typically very poor at turning them into valuable and useful information. Charts and tables, indexes and percentages are only useful if they are reviewed, interpreted and acted on. What does the information mean? Can the firm use the information in the next mailing selection or targeted marketing campaign? Can it build a statistical model? Was the analysis worthwhile? Would the firm do it again or would it do it again differently? Review after execution is vital if a company is to take the lessons learned from a campaign, put them to good use in subsequent campaigns and reap the rewards.

The key to long-term success in a company's campaign programme is, however, in evaluating whether a campaign will work in advance as well as evaluating its success in retrospect. Marketing campaign systems can help to improve the quality of campaigns by evaluating whether they are feasible before they even develop to the execution stage and when evaluating their potential profitability using these systems, it is evident that many should never be put into operation. When it is calculated what these unsuccessful campaigns could have cost the organisation, it is clear that they provide companies with a fast return on their investment. This is vital as 68 per cent of the marketing executives surveyed in the Accenture study said that their companies are unable to measure a marketing campaign's return on investment. $^{8}$

Using a marketing campaign system it is possible to enter cost details for each element of a campaign, enabling users to also test the potential profitability of a campaign before initiation. As a result, companies are able to determine the kind of response they need for financial viability and the target audience they should aim for to achieve the target. Their interactive nature also allows the marketer to understand the impact that reducing or increasing costs will have on the breakeven response rate required. This breadth of functionality, from profiling the campaign targets to confirming profitability, highlighted in Figure 4, disproves the common belief that marketing campaign systems are mainly about the mechanical processes of executing campaigns. While they are more than able to do this, the real value-added benefits come from the powerful planning capabilities they provide.

\section{BECOMING CUSTOMER-FOCUSED}

Business is very simple. It is all about turning prospects into customers and low-value customers into high-value customers, as shown in Figure 5. It is about harnessing customer information and then interpreting that information in the most efficient manner using specialist expertise and acting upon it. By understanding its customers and prospects a firm can then take action which is both relevant and cost effective.

Unfortunately, companies typically forget that the basics are simple. As a 


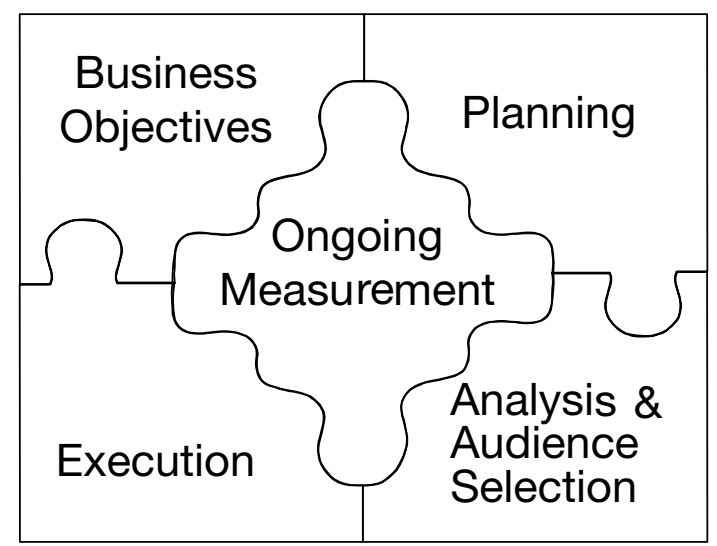

Figure 4: Stages and processes

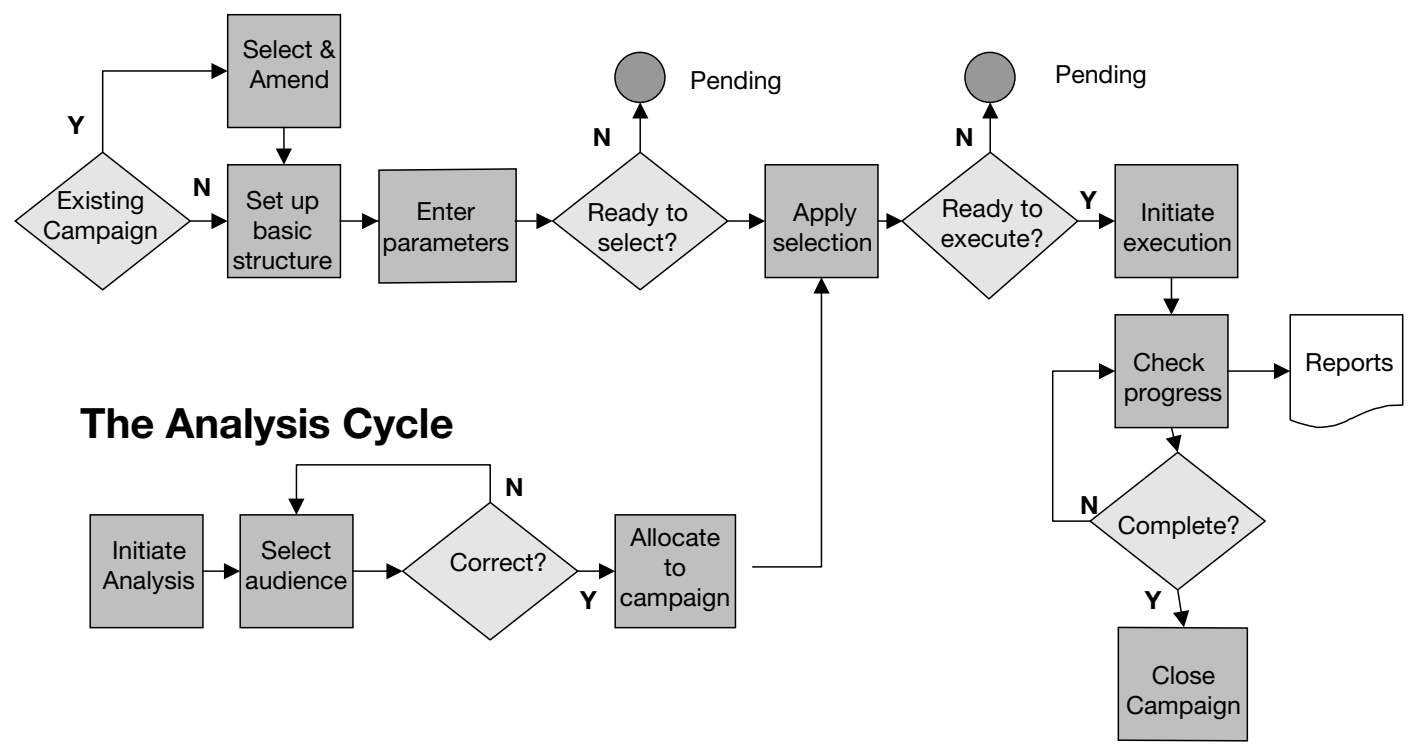

Figure 5: The campaign cycle

consequence, they over-complicate both analysis and marketing campaign management. Preferring to settle for the status quo, coupled with the prospect of number crunching and complex analysis, marketers are quickly persuaded that the path of least resistance - not doing it at all - is preferable.

The key to effective marketing campaigns, however, is analysing the customer database and customers' buying behaviour to identify the common attributes of those customers who have the best lifetime value. It is widely quoted within the direct marketing industry that obtaining new customers cost six times more than the effort to retain current customers. Common experience in marketing circles has proved the Pareto Principle (or the 80:20 rule): 80 per cent of an organisation's profits come from 20 per cent of its customers, with 50 per cent of its profits eaten away by the bottom 30 per cent. 
The conclusion is clear. By identifying its most profitable customers a firm can effectively reduce spending on low-profit customers and concentrate efforts on growing the top 20 per cent of its customer base.

Marketing campaign systems can help organisations identify the current and potential value of customer relationships and subsequently determine where and how to best allocate marketing spend to improve their value. Query selection tools, including advanced CHAID modelling routines, help companies choose the most likely target audience for any given product or service offering, and powerful suppression modules prevent damaging actions such as 'do not mail', 'already purchased product' and 'already contacted' situations.

Advanced customer profiling, statistical predictive model building, clustering and segmentation and profitability analyses can all be used to provide a richer and usable picture of customers. Cross-selling opportunities, the development of customer spend and loyalty, customer lifetime value calculations and customer recruitment and retention plans can then be easily identified. This ensures the best possible target audience selection for maximum response results. It also helps companies shift away from the typical emphasis on product productivity towards a focus on customer understanding and profitability. Most importantly, it puts this customer understanding firmly on the marketing department desktops, rather than in the queue for IT analysts.

Successful analysis provides more than quick fixes though. Businesses have traditionally been focused on marketing techniques, manufacturing processes and economies of scale and have typically grown too big to maintain close relationships with their customers. Campaign management techniques and marketing campaign systems, however, can help businesses of all sizes develop, maintain and enhance customer relationships and ensure customer loyalty. They allow companies to gain a deeper understanding of their customers and make better decisions, resulting in profit due to either increased revenue or reduced costs. By using analysis, large companies can also begin to behave as nimbly as small companies, counteracting the common danger that the bigger a company gets, the more remote it becomes from its customers.

\section{STOP HESITATING, START ACTING}

The benefits of marketing campaign systems are evident. Faster, better and easier marketing campaigns. Response rates to mailings improve, direct marketing programmes are increasingly successful and campaign hit rates increase. Importantly, marketers understand their customers better, leading to the delivery of better campaigns and increased customer loyalty.

So, why are companies still hesitating? The short life cycle of marketing staff in the economic downturn is one reason. The high attrition rate of staff is resulting in a lack of continuity regarding marketing efforts and a skills gap. Companies need hybrid people who are literate in data, technology and marketing and they are increasingly difficult to find. Increased pressure on marketing budgets in the current economic climate also means companies are often waiting for the 'perfect' corporate solution to arrive - robust enough to cope with the multiple demands placed upon it, able to offer the whole range of functionality, including campaign evaluation, pre-planning, execution, evaluation and analysis. The advice? Firms should not wait. By hesitating they are losing valuable ground 
to competitors, missing sales

opportunities and losing customers.

There is also a tendency for marketers to focus on the more 'sexy' elements of marketing campaigns such as the design and creative elements. The 'nuts and bolts' of the technology are avoided and a lack of technical skills and confidence dissuades marketers from getting involved. As a result, implementing a marketing campaign system may require contact with colleagues in other business units. There is a general reluctance to embark on this when staff consider themselves too busy already.

Cost is also an issue. Firms are concerned about implementation costs but in the same breath also tend to underestimate the complexity and resources required to address the project. What is often forgotten is that users have to learn how to use marketing campaign systems but, more importantly, to understand the relevance of the tool. What is it going to do for them? How will their understanding of customers change? What will the impact be on customer loyalty or revenue? Without this fundamental understanding, marketers will view marketing campaign systems as tools to automate and speed up existing marketing processes and little else.

Perhaps most importantly of all, marketing campaign systems bring campaign management under the control of the marketing function rather than the IT department. This presents a clear paradigm shift and an extremely strong argument in favour of implementing a system sooner rather than later. Many companies plan a marketing campaign but leave it to the IT department to manage the detailed selection and extraction of the data for mailing. Marketing campaign systems enable marketers to keep this process within the management of the overall campaign, making execution so easy to use that outside IT help is often not required. This encourages marketers to adopt a more commercial approach and attitude to marketing efforts and vastly improves the management and transparency of the process from start to finish. This also ensures valuable lessons learnt from retrospective campaign analysis are fed back directly to the people responsible for future campaigns - invaluable for today's marketers, who are under pressure from other functions of the organisation to provide faster, better-planned and more profitable marketing campaigns.

\section{MAKING CUSTOMERS COUNT WITH A MARKETING CAMPAIGN SYSTEM}

The following is a customer case study illustrating the real-life effectiveness of marketing campaign systems and a dynamic marketing strategy in harnessing the value of customer data.

Leading financial services group, Britannic Assurance has 1.4 million policyholders. When it needed to gain a comprehensive understanding of its customers and their individual worth, it chose to implement a marketing campaign system. With the new system in place, the average hit rate of Britannic Assurance's sales campaigns has increased from 0.5 per cent to 1.4 per cent and has generated significant new business.

As a result of Britannic Assurance's drive towards a more performance-driven and customer-focused organisation, it recognised there was one particular hurdle - the lack of a comprehensive, centralised marketing database. This was hindering the company's attempts to analyse customer behaviour and target existing and prospective customers effectively.

Britannic Assurance knew it was missing sales and marketing opportunities and that it could improve its revenue and profit significantly if it had access to 
accurate customer information and profiles. The difficulty in gaining an overall picture of each customer and their individual value and potential for new sales was holding them back and as a consequence, any attempts at target marketing were also proving unsuccessful.

Britannic Assurance invested in a marketing campaign system with the help of external consultants. It began by consolidating its customer data into a single database and carried out data cleansing and data engineering to ensure a standard format. The database enables Britannic Assurance to gain a detailed view of each individual customer and future potential. Sophisticated modelling, analysis and segmentation can also be carried out to ensure that the company is proactive with new product sale opportunities and targeted marketing and advertising.

The system is also being used to support campaigns run by the company. David Taylor, Head of Marketing, explained: 'We have used it to help run our direct marketing campaigns and to better target our customers. We often run a direct mail campaign of 100,000 for example, but with 1.4 million active customers identifying which of the customer base are the best targets and are going to be most receptive to a particular offer and product is very difficult. The new system helps immensely'. Taylor concluded:

'Everything is now driven by our understanding of our customers. Deploying the database has enabled us to do a lot of strategic planning in terms of our business, sales force and territories. We can now access information about our customers quickly on our own system and our whole understanding has improved immensely. Time and cost savings have also been considerable because we don't have to raise an IT request to get code written every time we want to access our customer data. Marketing and campaign management is now firmly in the hands of marketers'.

\section{CONCLUSIONS}

In conclusion, the seven deadly sins of campaign management are:

- being product led rather than customer focused

- collecting data and not using them

— building disjointed activities not integrated ones

- not reviewing performance or learning from results

- not challenging the status quo

- being too focused on just response rates

- thinking tactically not strategically and forgetting the big picture.

In choosing a marketing campaign system it is important to ensure that the chosen system offers:

- robustness and flexibility to cope with multiple demands

— integrated analysis

— speed to meet campaign needs

— affordability

- extensive functionality

- ease of use

- a complementary, rather than defining, approach to existing marketing practices.

Rules for effective database marketing are:

- ensure it is known what data are available and are required

- gather all appropriate data from external and internal sources

— bring all the data into a consistent format

- correct any errors

- de-duplicate and combine data for the same customers 
- add pertinent data from external sources

- analyse data for most suitable selection for the product and feed results back for better future information.

\section{References}

1 PricewaterhouseCoopers (2001) 'Customer relationship management. A senior management guide to technology for creating a

customer-centric business' commissioned by The

Direct Marketing Association.
2 IDC (2001) 'Worldwide CRM applications, market forecast and analysis summary 2001-2005', August.

3 ICD (2000) 'Sizing the opportunity for CRM-centric data warehousing software and services', July.

4 PricewaterhouseCoopers (2001) op. cit.

5 O'Halloran, P., Wagner, T. R., Ansusinha, T., Lawrence, R. and Quiring, K. N. (2001) 'Insight driven marketing - Using customer insights to build brand loyalty and increase marketing ROI', Accenture.

6 Ibid.

7 Ibid

8 Ibid. 